\title{
A PRESENÇA DOS AUTORES DAS CIÊNCIAS SOCIAIS E HUMANAS NO CAMPO DA BIBLIOTECONOMIA E DA CIÊNCIA DA INFORMAÇÃO
}

\author{
Gabrielle Francinne de S. C. Tanus ${ }^{1}$ \\ Universidade Federal do Rio Grande do Norte \\ gfrancinne@gmail.com \\ Amanda Ingrid Silva de Aguiar \\ Universidade Federal do Rio Grande do Norte \\ amanddaaguiiar@gmail.com
}

\begin{abstract}
Resumo
Apresenta uma análise preliminar das manifestações dos autores das Ciências Sociais e Humanas dentro do campo da Biblioteconomia e da Ciência da Informação (B \& C.I.), por meio do método bibliométrico e análise de citação. Com o objetivo de descortinar quais teóricos são convocados para a construção do conhecimento na produção científica dos campos supracitados, realizou-se uma pesquisa exploratória com vistas ao levantamento dos autores das Ciências Sociais e Humanas e, posteriormente, a verificação da ocorrência deles na produção indexada pela Base de Dados em Ciência da Informação (BRAPCI). Foram identificados 180 autores, dos quais 91 apareceram pelo menos uma vez nas buscas empreendidas pelos nomes e sobrenomes desses autores das Ciências Sociais e Humanas. O resultado desta pesquisa demonstrou os dois autores mais citados, Michel Foucault e Pierre Bourdieu, bem como a presença de diversos autores das Ciências Sociais e Humanas na construção do conhecimento da Biblioteconomia e da Ciência da Informação, o que contribui para o fortalecimento e a consolidação de ambas.
\end{abstract}

Palavras-chave: Ciências Sociais e Humanas. Biblioteconomia. Ciência da Informação. Epistemologia. Análise de citação.

\section{THE AUTHORS PRESENTS OF SOCIAL AND HUMAN SCIENCES IN THE FIELD OF LIBRARY AND INFORMATION SCIENCE}

\begin{abstract}
It presents a preliminary analysis of the manifestations of the authors of Social and Human Sciences within the field of Library and Information Science (B\&CI), through the bibliometric method and citation analysis. In order to unveil which theorists are called for the construction of knowledge in the scientific production of the above fields, an exploratory research was conducted with a view to survey the authors of the Social and Human Sciences and, subsequently, to verify their occurrence in indexed production. Information Science Database (BRAPCI). A total of 180 authors were identified, of which 91 authors appeared at least once in searches carried out by the names and surnames of these authors of the Social and Human Sciences. The result of this research demonstrated the two most cited authors, Michel Foucault and Pierre Bourdieu, as well as the presence of several authors from the Social and Human Sciences in the construction of knowledge of Library and Information Science, which contributes to the strengthening and consolidation. of both.
\end{abstract}

Keywords: Social and Human Sciences. Library Science. Information Science. Epistemology, Citation Analysis.

\footnotetext{
1 Professora do Departamento de Ciência da Informação da Universidade Federal do Rio Grande do Norte (UFRN). Mestra e Doutora em Ciência da Informação (UFMG). Atuou como bibliotecária do Sistema de Bibliotecas da UFMG.

${ }^{2}$ Discente do curso de Biblioteconomia da Universidade Federal do Rio Grande do Norte. Bolsista de Iniciação Científica do projeto "Discursos Contemporâneos da Biblioteconomia".
} 


\section{INTRODUÇÃO}

A capacidade de abstração é inata do ser humano, e constitui uma habilidade fundamental para a construção da informação e do conhecimento. A Filosofia, matriz primeira de todas as Ciências, tem sua origem associada à Antiguidade, e ao lado deste conhecimento científico foram surgindo diversas outras formas de conhecimentos, como, por exemplo, empírico, tácito, religioso e senso comum. A fé e a teologia consistiam no ponto de partida para a formulação e o controle do conhecimento na Idade Média. Posteriormente, na Idade Moderna, nomes como Copérnico, Kepler, Bacon, Galileu, Descartes e Newton são centrais para a construção e consolidação da ciência moderna, que nasce amparada pelo método científico, fundamentado na racionalidade, na observação, na lógica e na objetividade, diferenciando o conhecimento vulgar e religioso do científico, sendo este o conhecimento sistemático, marcado por um rigor metodológico e passível de generalizações (FARA, 2015).

Influenciado pela lógica das Ciências Naturais e Biológicas, Augusto Comte, fundador do Positivismo, primeira corrente de pensamento das Ciências Sociais, cunhou o termo Sociologia, ciência esta que objetivava olhar para sociedade e seus desdobramentos a partir de um método racional e científico. Estava posto, portanto, o caminho em busca da compreensão da sociedade, que foi também objeto de estudo de Émile Durkheim, que estabeleceu o "fato social" como objeto de estudo da Sociologia, ainda no século XIX.

Ademais, diversos outros pensadores participaram da construção das Ciências Sociais, dentre eles os precursores Karl Marx e Max Weber, tendo cada um deles uma maneira específica de olhar para a realidade e as relações sociais. Esse três - Durkheim, Marx e Weber - constituem a tríade dos autores fundadores e clássicos das Ciências Sociais, notadamente marcada por uma multiplicidade de autores e correntes teóricas. A complexidade do conhecimento possibilitou a manifestação de diversos outros saberes e campos científicos, que passaram a ser sistematizados contemporaneamente em grandes áreas, como por exemplo: Ciências Exatas e da Terra; Ciências Biológicas; Engenharias; Ciências da Saúde; Ciências Agrárias; Ciências Sociais; Ciências Humanas, Linguística, Letras e Artes.

As Ciências Humanas, como uma grande área, abriga diversos campos científicos que devotam o olhar para os conhecimentos desenvolvidos pelo pensamento crítico centrado nos sujeitos, nos seres humanos, em suas individualidades e sociabilidades. Segundo Marilena Chauí (2002), o homem como objeto científico surgiu no século XIX; até esse século a Filosofia estudava e tratava de tudo relacionado ao ser humano. Foucault (1999), em sua obra seminal “As palavras e as coisas", expõe o nascimento do homem como objeto de estudo a partir da 
positividade do discurso da biologia, da economia política e da filologia, assentando o ser humano que vive, trabalha e fala (linguagem), e que representa e é representado, sendo o ponto de constituição das próprias ciências humanas. Dentre os exemplos de campos científicos dentro dessa área das Ciências Humanas estão: História, Antropologia, Filosofia, Psicologia.

A complexidade de olhar para o indivíduo e para a sociedade possibilitou a construção de diversas escolas de pensamentos e agrupamentos das teorias nas correntes teóricas das Ciências Sociais e Humanas, como estabeleceu Lallement (2008): ordenamento do social, contradição do social e construção do social, tendo cada uma dessas escolas características que se sobressaem e se diferenciam uma das outras. O ordenamento do social é marcado pela centralidade na ordem, no progresso social, na realidade externa e acabada, e não adentra nos conflitos, nas ideologias, na luta de classes, que é a tônica da contradição do social, marcada também pela consciência histórica dos saberes. A construção do social centra no indivíduo e nas ações sociais como construtores das realidades e das relações sociais; o foco é no microssocial, em vez do macrossocial, modo de olhar das duas primeiras correntes de pensamento.

A Biblioteconomia e a Ciência da Informação, que são outros dois campos científicos ${ }^{3}$ integrantes das Ciências Sociais, são também nomeadas de "campos informacionais" (MARTELETO; SALDANHA, 2016), dedicados ao "olhar informacional" e as "responsabilidades sociais" no que se refere à informação nos múltiplos ambientes e contextos, bem como vinculada aos processos de organização, armazenamento, disseminação, mediação e apropriação da informação. Todavia, ambas diferenciam-se qualitativamente devido às trajetórias históricas, teorias e metodologias convocadas para a solução de problemas (SARACEVIC, 1996). Embora ambas, inseridas no rol das ciências, tragam as marcas do próprio desenvolvimento mais amplo dos saberes sociais onde se inserem como modalidades específicas, a Biblioteconomia é marcada discursivamente pelos três momentos supracitados: ordenamento, contradição e construção do social (TANUS, 2018), enquanto a Ciência da Informação também o é por meio da concepção dos paradigmas físico, cognitivo e social (CAPURRO, 2003), que ancoram-se nas teorias das Ciências Sociais, isto é, no positivismo, no cognitivismo e no sociológico (FERNÁNDEZ MOLINA; MOYA-ANEGÓN, 2002).

Em relação à história da Biblioteconomia, salienta-se que ela surgiu como saber empírico ainda na Antiguidade, vinculada às práticas exercidas nas bibliotecas, o que

\footnotetext{
${ }^{3}$ Como formulado por Pierre Bourdieu (2012), considera-se ambos os campos científicos distintos como um espaço de lutas, de forças, de embates concorrenciais travados dentro do universos social, macrocosmo, sendo regidos por leis específicas em prol da autoridade e competência científica.
} 
conformou este momento como Biblioteconomia pré-científica, depois nomeada de Biblioteconomia proto-científica e Biblioteconomia científica (TANUS, 2016). No contexto da Segunda Guerra Mundial nasceu a Ciência da Informação, voltada para os problemas da explosão informacional e dos registros do conhecimento para além do livro, tendo como aliada as tecnologias de informação e comunicação (SARACEVIC, 1996). A Ciência da Informação apresenta como uma de suas características uma diversidade de teorias que convoca, bem como uma fecunda relação desde sua origem com a Biblioteconomia, sobretudo devido aos conhecimentos relacionados com a organização da informação, responsabilidade social e acesso à informação. Em particular no Brasil, a própria institucionalização da Ciência da Informação entremeia-se com a infraestrutura cognitiva, institucional e social da Biblioteconomia, de modo que no âmbito da produção científica ambos os campos utilizam-se dos mesmos veículos formais de comunicação científica, como os periódicos científicos e os eventos que abrangem a Biblioteconomia e a Ciência da Informação.

Nesse contexto, de intensas proximidades interdisciplinares entre a Biblioteconomia e a Ciência da Informação dentro do rol das Ciências Sociais, partiu-se da hipótese de que tais campos convocam os autores das Ciências Sociais e Humanas para a sua produção de conhecimento. Diante disso, definiu-se o seguinte problema de pesquisa: quais autores das Ciências Sociais e Humanas são convocados pela Biblioteconomia e Ciência da Informação para a sua produção do conhecimento? Foi estabelecido o seguinte objetivo geral: identificar a presença de autores das Ciências Sociais e Humanas na produção científica da Biblioteconomia e Ciência da Informação indexada em base de dados nacional em Ciência da Informação. Para tanto se empreendeu uma pesquisa bibliométrica na Base de Dados em Ciência da Informação - BRAPCI. "Em termos de análise métrica dos produtos da comunicação acadêmica, os pesquisadores apenas podem processar o que foi publicado e o que está disponível" (WOLFRAM, 2017, p. 94), sendo, portanto, o caminho metodológico o da identificação quantitativa a partir da análise de citação dos trabalhos que citaram os autores das Ciências Sociais e Humanas.

A importância deste trabalho recai em identificar os autores citados advindos das Ciências Sociais e Humanas, e que constituem as bases de citação dos conhecimentos produzidos pela Biblioteconomia e Ciência da Informação. Percebeu-se que a identificação bibliométrica a partir da análise de citação é um território que vem sendo desenvolvido e apresentado em diferentes pesquisas que buscam também conhecer o impacto de certos autores na produção do campo, como, por exemplo, pesquisas que se concentram nos autores da própria Biblioteconomia e Ciência da Informação: J.H. Shera (ARAUJO; LAGE; SOUZA; ASSIS, 
2010); Kuhlthau (ARAUJO; BRAGA; VIEIRA, 2010) e Tefko Saracevic (PINHEIRO; SILVA; ARAUJO, 2011), entre outros estudos. Ademais, vale a pena destacar o livro "Critical theory for library and information Science: exploring the social from across the disciplines" (2010), que buscou demonstrar a importância de vários autores das Ciências Sociais e Humanas na constituição teórica e crítica da Biblioteconomia e Ciência da Informação. Dentre os autores destacados estão: Michel Foucault, Jürgen Habermas, Pierre Bourdieu, Gilles Deleuze.

O processo de citação não é uma atividade ingênua, desprovida de efeitos; pelo contrário, a escolha e o ato de citar são escolhas políticas e impactam na comunicação científica, gerando consequências como a visibilidade, a credibilidade e o reconhecimento da obra e do autor citado. Assim, discutir sobre os motivos da citação é um campo fecundo de pesquisa dentro da Biblioteconomia e Ciência da Informação, tendo como um dos principais métodos a bibliometria, que consiste na sistematização das frequências, ou melhor, das ocorrências dos elementos informacionais. Todavia, sem adentrar nas manifestações propriamente ditas do texto citado, opera-se aqui com o desvelamento da primeira camada, a investigação das autorias presentes na produção da Biblioteconomia e Ciência da Informação a fim de mobilizar a discussão dos diálogos, dos cruzamentos, das interações entre os autores convocados para o desenvolvimento das produções científicas dos referidos campos supracitados.

\section{A BIBLIOMETRIA COMO MÉTODO PARA AS PESQUISAS EM BIBLIOTECONOMIA E CIÊNCIA DA INFORMAÇÃO}

A bibliometria é um dos métodos quantitativos dos estudos métricos que compõem o rol metodológico comumente convocado pela Biblioteconomia e Ciência da Informação. Ao pesquisar o termo bibliometria na base brasileira de periódicos em Ciência da Informação (BRAPCI), o resultado foi expressivo: mais de 500 trabalhos foram recuperados. Ao operar com a busca com o termo em inglês, Bibliometric, na base de dados internacional Library and Information Science Abstract (LISA), foram recuperados mais de cinco mil artigos publicados em periódicos acadêmicos. Os resultados expressivos demonstram que a bibliometria é utilizada na área para o desenvolvimento diverso de pesquisas, sendo discutida de modo pioneiro por Paul Otlet, em seu "Tratado de Documentação", de 1934, antes mesmo da consolidação da Ciência da Informação.

Ao lado da bibliometria, isto é, dos estudos métricos, destacam-se também outros procedimentos metodológicos e epistemológicos com objetivos diferentes, a saber: a cienciometria, a webometria, a informetria e, mais recentemente, a altmetria ou métricas 
alternativas, que demonstram o vigor dos estudos ao abordarem os novos ambientes informacionais. No contexto de desenvolvimento da bibliometria associam-se as leis de Lotka (produtividade de autores), de Bradford (dispersão de periódicos) e de Zipf (frequência de ocorrência de palavras), o que sinaliza o uso estabelecido de suas bases teóricas. Particularmente sobre a bibliometria, considera-se como uma das técnicas de análise quantitativa que mede a difusão da produção do conhecimento científico registrado, usando-se seus resultados para dar suporte ao planejamento e a tomada de decisões em diferentes contextos. O objeto de estudo da bibliometria consiste nos livros, documentos, periódicos, autores, usuários, tendo como variáveis os números de empréstimos, de citação, de frequência de extensão de frases, e cujo método é a frequência, distribuição, ranking (VANTI, 2002).

A bibliometria é, portanto, uma técnica de análise que usa conceitos da estatística e da matemática para extrair diversas informações do material selecionado/analisado, cabendo ao pesquisador definir os objetivos e a melhor estratégia para a coleta dos dados, que pode ainda combinar com outros métodos e técnicas de coleta de dados. Outro método que se quer destacar é a técnica de análise de citação, a qual foi aqui também empreendida, e que em outro momento deverá ser mais verticalizada, ensejando inclusive a análise dos discursos. A leitura dos discursos para além do mapeamento quantitativo possibilitaria extrapolar a identificação das ocorrências dos autores com vistas à compreensão de como e os porquês os autores e as obras são citadas e apropriadas pelos autores da Biblioteconomia e Ciência da Informação.

Sobre a análise de citação, uma das possibilidades bibliométricas, destaca-se que por meio da identificação, ou melhor, da mensuração dos autores citados e dos documentos citantes se extrai o mapeamento da comunicação científica de uma área do conhecimento (VANZ; CAREGNATO, 2003). Outras variáveis são possíveis por meio da análise de citação como o desvelamento dos autores mais citados, mais produtivos, elite de pesquisa, frente de pesquisa, fator de impacto, procedência geográfica e/ou institucional dos autores, bem como as fontes e tipos de documentos mais utilizados, idade média da literatura e obsolescência, entre outros elementos (ARAÚJO, 2006). Retomando a análise de citação, considera-se que as citações reflitam uma influência do autor e da obra citada nos artigos científicos, os quais geralmente passam ainda por uma avaliação às cegas da comunidade científica que, mais uma vez, legitima a produção textual e os autores convocados para a elaboração dos trabalhos.

Uma citação pode corresponder tanto a um informe teórico, conceitual ou metodológico de uma contribuição citada, quanto a diversas motivações dos autores que citam algum trabalho, que serve tanto para exemplificar, corroborar ou refutar o pensamento do autor ou mesmo por vaidade no caso de algumas autocitações (SILVEIRA; CAREGNATO, 2014, ROMANCINI, 
2010). Na verdade, existem diversos motivos de citação, que são inclusive foco de estudos e pesquisas na área. A busca por essas interpretações conduzem a uma aproximação dos estudos quantitativos a uma abordagem qualitativa, com vistas a adentrar nas motivações e nos impactos que levam um autor a citar outro autor(a), possibilitando uma abertura de um outro olhar para os números que derivam dos estudos métricos e que às vezes tornam-se limitadores nas análises. Como outra atividade humana, desde a produção do trabalho, passando pela seleção dos autores e textos citados, está imbricada a subjetividade da escolha em meio aos diversos contextos que permeiam a atividade científica, que também precisa de modo vigilante convocar o pensamento crítico para uma compreensão mais ampla dos processos de elaboração da ciência.

\subsection{A importância da citação: configurações bibliométricas}

Um campo de pesquisa é compreendido a partir da institucionalização de práticas de pesquisa em que os cientistas comunicam seus achados; isso acontece desde a criação dos periódicos no século XVII, os quais possuem a função de compartilhamento científico entre os pares (BUFREM, 2018). A importância dos periódicos como forma de comunicação formal na contemporaneidade está vinculada a uma diversidade de funções como, por exemplo: registrar o conhecimento; disseminar o conhecimento; preservar o conhecimento registrado; visibilizar a produção; salvaguardar os achados da pesquisa; defender e legitimar o pensamento; servir como fonte de informação; servir de mecanismo de controle de um campo do conhecimento, fonte para os estudos métricos, da bibliometria a altimetria, etc.

O discurso científico e a citação são elementos que constituem e consolidam um campo científico, configurando uma "genealogia acadêmica", pois os campos se ancoram nas pesquisas desenvolvidas e compartilhadas entre seus pesquisadores, em um processo de retroalimentação (BUFREM, 2018). Nessa direção, o campo científico é permeado de luta que reverbera inclusive nas práticas de citação dos artigos científicos, sendo essas disputas e concorrências próprias da ciência, com o intuito de se constituir uma competência científica por meio da capacidade técnica e o poder social conferido ao cientista (BOURDIEU, 2012). Os estudos de aferição das citações, como já dito, apresentam uma miríade de publicações nacionais e internacionais, o que direciona a apresentação de alguns estudos que se aproximam da problemática proposta neste trabalho. Assim, visibilizam-se, aqui, por meio da citação, os trabalhos acadêmicos que apresentam uma contribuição de determinados autores das Ciências Sociais e Humanas (os quatro mais citados) para a construção discursiva da Biblioteconomia e Ciência da Informação brasileira. Contudo, não se apresenta um esgotamento, já que conforme 
a seção seguinte são centenas de trabalhos que mobilizam os autores das Ciências Sociais e Humanas, que devem ser objeto de análise mais profunda por pesquisas futuras.

A arqueologia do saber de Michel Foucault, como instrumental teórico para as pesquisas em Ciência da informação, é convocada para a construção da análise dos discursos, em que um dos caminhos é justamente pela via dos estudos métricos, abordados por Alvarenga (1999) a partir da bibliometria. Nos estudos de Lígia Freitas (2001) envolvendo a análise do discurso e a Ciência da Informação, a autora chama atenção para o momento arqueológico de Foucault. Na verdade, a influência foucaultiana não se encerra nessas citações, muito pelo contrário: este autor encontra-se citado nas pesquisas da área a partir de diversas produções, demonstrando uma diversidade de apropriações de seus conceitos que embasam a construção discursiva da Biblioteconomia e Ciência da Informação, por meio dos conceitos de poder, dispositivo, saber, discurso, sujeito, conhecimento, arquivo, etc.

Alves e Oliveira (2017) analisaram os artigos publicados por pesquisadores de produtividade da Ciência da Informação entre os anos de 2011 a 2016, utilizando os conceitos de Pierre Bourdieu como base teórica. Assim, a partir do estudo bibliométrico pode-se chegar aos dominantes e/ou dominados, como também foi mobilizada a teoria do campo científico e os conceitos de capital social e capital científico para a interpretação da análise das redes sociais. Destaca-se também o E-book "Pierre Bourdieu e a produção social da cultura, do conhecimento e da informação" (2017), organizado por Regina Marteleto e Ricardo Pimenta (IBICT-UFRJ), que demonstra a partir da coletânea de capítulos a apropriação das teorias de Bourdieu nas áreas da Ciência da Informação, Comunicação e Saúde, entre outras. Do mesmo modo, o livro “A Ciência da Informação encontra Bourdieu” (2017), organizado por Elaine Rosangela de Oliveira Lucas e Murilo Artur Araújo da Silveira (UFPE), reforça o legado e o fortalecimento das bases sociais da Ciência da Informação a partir da produção teórica e dos conceitos daquele autor.

A teoria crítica de Habermas subsidia a construção de várias pesquisas na Biblioteconomia e Ciência da Informação, como, por exemplo, a manifestação da teoria da ação comunicativa e da esfera pública nos estudos de Siebeneichler (2014), Zattar e Lima (2013), Fell et al (2014); a compreensão dos paradigmas da Ciência da Informação a partir da teoria crítica de Habermas é o foco de Castro e Silva (2016), entre outros autores e trabalhos. O evento Colóquio Habermas, promovido desde 2008, constitui um espaço particular de discussão e receptividade da obra do autor no âmbito da Ciência da Informação. Esse evento passou a integrar ainda o Colóquio de Filosofia da Informação, compondo um espaço fértil para as discussões epistemológicas pautadas por uma teoria crítica a partir de diversas abordagens 
expressas pelos autores das Ciências Sociais e Humanas. Cabe ainda destacar os artigos da Revista Logeion: Filosofia da Informação, editada pelo IBICT, que tem como foco divulgar e valorizar a pesquisa em Filosofia da Informação, e que trouxe diversos artigos acerca da obra do filósofo alemão Jurgen Habermas em edição especial (volume 5, 2018).

Amorim e Medeiros (2018) abordam a produção de Gilles Deleuze no contexto da Ciência da Informação, investigando os conceitos do filósofo de "escola" e "movimento", localizando no contexto das Ciências Sociais e suas relações inter e transdisciplinares com outros saberes, destacando seu laço com a Filosofia. Nesse estudo, os autores demonstram a apropriação do pensamento de Deleuze a partir de um estudo bibliométrico, que verificou a ocorrência desse autor na produção nacional e internacional da área a partir da busca em duas bases de dados, BRAPCI e LISA. Assim, foram identificados 39 e 14 artigos respectivamente nas referidas bases de dados, ocorrendo a primeira citação de Deleuze nos artigos da área na década de 1990, e tendo a "organização do conhecimento" uma forte apropriação da filosofia deleuziana. A autora nacional que mais cita Deleuze é Solange Mostafa, destacando-se os livros “Para ler a filosofia de Gilles Deleuze e Félix Guattari”, publicado em 2009, de sua autoria e de Denise Viuniski da Nova Cruz, e mais, recentemente, "Filosofia da diferença e a Ciência da Informação", publicado em 2013.

Arboit, Bufrem e Freitas (2010) investigam os artigos de periódicos indexados na BRAPCI com o objetivo de analisar as citações da produção que versa sobre epistemologia da Ciência da Informação entre o período de 1972 e 2008. As autoras identificaram 95 artigos para a composição do corpus da pesquisa e com a análise apontam os autores da área mais produtivos, bem como os autores mais citados dessa produção. Assim, para além dos próprios autores da área presentes, há o registro dos autores basilares das Ciências Sociais e Humanas que contribuem para essa fundamentação epistemológica da Ciência da Informação. Dentre os teóricos mais citados estão: Edgar Morin, Bruno Latour, Thomas Kuhn, Foucault, Boaventura Santos, Japiassu, Lakatos, Popper, Bachelard, Prigogine, Castells, Feyerabend, Moles e Habermas. As autoras sinalizam que há uma "diversidade de linhas de pensamento adotadas pelos autores levantados demonstrando intenso pluralismo presente no campo teórico da Ciência da Informação" (ARBOIT; BUFREM; FREITAS, 2010, p. 33), e que a epistemologia da CI acompanhou as tendências de debate no campo epistemológico das ciências de modo mais amplo, o que se confirma pela influência de filósofos e sociólogos.

Em outro estudo, além dos autores mais citados, Bourdieu, Morin, Levy, Castells e Eco também marcaram presença nas citações dos artigos publicados na revista Ciência da Informação, editada pelo IBICT, durante o período de análise compreendido entre 1972 e 2007. 
Isso demonstra a influência de autores que são clássicos de Ciências Sociais, que de maneira direta ou indireta, compõem o corpus teórico da Ciência da Informação (SHIKIDA, 2012). Outra pesquisa bibliométrica que aponta a presença dos autores das Ciências Sociais é a análise dos artigos que versam sobre gestão da informação que foi objeto de estudo de Kroeff et al (2015). No que se refere a análise de citação dos artigos indexados pela base BRAPCI, durante os anos de 200 a 2011, foram identificadas mais de quatro mil referências, apresentando dentre os autores das Ciências Sociais mais citados Pierre Lévy e Manuel Castells.

Em pesquisa mais recente Francelin (2018) focaliza na produção científica da Ciência da Informação em epistemologia, apresentando os autores de destaque e os principais referenciais teóricos citados. O levantamento dos artigos se deu em 30 periódicos, no período de 1972 a 2015. Foram analisados 164 artigos no total, evidenciando um aumento de publicações a partir de 2004, com uma intensa produção entre 2010 e 2015, período que concentrou 81 artigos. Interessante ainda perceber que, das 30 revistas, 24 delas apresentaram pelo menos um artigo voltado para a epistemologia, e novas revistas tem contribuído para esse espaço de publicação. Francelin (2018) constata que a pesquisa em epistemologia vem aumentando no país, tendência que fica ainda mais nítida quando se compara com os resultados dos artigos que compuseram o corpus da pesquisa das autoras Arboit, Bufrem e Freitas (2010). Dentre os autores das Ciências Sociais e Humanas com mais de cinquenta citações está Edgar Morin, havendo uma predominância a partir desse recorte quantitativo dos autores próprios da Ciência da Informação como os sujeitos mais citados. Apesar de não problematizar os autores das Ciências Sociais nessa produção, Francelin (2018) reforça a importância da constituição de publicações, pesquisas, grupos de pesquisas centrados na construção do conhecimento filosófico e científico.

Dentre o referencial teórico mais citado por pesquisadores bolsistas de produtividade da Ciência da Informação, Bufrem (2018) revelou que Bourdieu é o quarto autor mais citado, estando atrás de Saracevic, González de Gómez e Aldo Barreto, sendo todos esses três autores da Ciência da Informação. Ao lado de Bourdieu estão também outros autores que marcaram presença nas pesquisas da Biblioteconomia e Ciência da Informação: Castells, Habermas, Foucault, Wersig, Latour e Morin. A pesquisa, portanto, demonstra que são convocados para a construção epistemológica autores das Ciências Sociais e Humanas, e que a construção de um objeto de pesquisa não é uma questão empírica, apoiando-se fundamentalmente na dimensão teórica, importando reconhecer as limitações descritivas e explicativas da própria Ciência da Informação (BUFREM, 2018, p. 55). 
Em síntese, os estudos bibliométricos supracitados que versam sobre a análise de citação demonstram a presença dos autores das Ciências Sociais e Humanas na construção dos artigos publicados, os quais reforçam tanto a Biblioteconomia quanto a Ciência da Informação enquanto Ciências Sociais - que convocam outros referenciais teóricos do campo maior onde se localizam. A citação dos autores sociólogos e filósofos é considerada muito positiva para o fortalecimento desses campos científicos, ampliando a visão de mundo ao relacionar outros autores, bem como possibilita uma maior verticalização de conceitos e teorias que são apropriados e ressignificados segundo o olhar da Biblioteconomia e Ciência da Informação. Importante frisar que a presença destes autores das Ciências Sociais não decorre apenas da necessária discussão acerca do objeto de estudo dos campos, extrapolando a apreensão dos conceitos e teorias para além da informação e suas imbricações nas mais diferentes temáticas, as quais ambas se debruçam a responder a partir das pesquisas científicas.

\section{METODOLOGIA E RESULTADOS}

Para encontrar e sistematizar os autores das Ciências Sociais e Humanas foi necessária, nesse primeiro momento, a consulta na internet dos nomes dos autores. Também foi realizado um levantamento dos nomes nas seções de Sociologia e Filosofia em uma biblioteca de ensino superior, a Biblioteca Central Zila Mamede (BCZM), da Universidade Federal do Rio Grande do Norte. O objetivo primeiro dessa atividade foi o de produzir uma lista com os nomes dos autores que compõem a produção teórica das Ciências Sociais e Humanas. A escolha da biblioteca se deu em virtude da localização institucional das autoras, que puderam coletar os nomes a partir da visita em tais seções, extrapolando a consulta ao catálogo online.

Após o levantamento na BCZM e na internet chegou-se a delimitação de 180 autores, dentre sociólogos e filósofos. Partiu-se, então, para a pesquisa na base BRAPCI por meio da busca pelo nome e sobrenome dos autores levantados previamente. A busca ocorreu no campo "default" da base, que cobre os campos de título, palavra-chave e resumo das produções científicas. Essa base de dados foi selecionada devido a sua importância, tendo em vista que indexa 57 revistas científicas, 19.255 trabalhos em revistas científicas, 2.592 trabalhos em eventos; dois livros e uma tese, contemplando cerca de 16.706 autores. O parâmetro adotado para a pesquisa foi a busca entre os anos de 1972 a 2019, o que corresponde a toda cobertura da base até o presente momento da coleta de dados. Vale ressaltar que a intenção foi verificar a presença dos autores para além dos estudos de epistemologia, isto é, buscou-se identificar a presença dos teóricos das Ciências Sociais e Humanas nas publicações científicas indexadas na 
BRAPCI como um todo, sem a prévia delimitação temática dos artigos, partindo pela busca pelos nomes dos autores levantados no primeiro momento deste estudo.

Desse modo, no campo "busca” a recuperação vincula-se à pesquisa no título, palavraschaves e resumo, onde foram submetidos os sobrenomes dos autores um a um, e quando necessário foi colocado o nome e o sobrenome entre aspas para fechar a expressão de busca. Registre-se ainda que foi necessário avaliar cada resultado de busca a partir da consulta do referido autor das Ciências Sociais e Humanas, pois houve casos de coincidência de sobrenomes que não correspondiam ao autor pesquisado, como os sobrenomes Freire e Weber. Assim, com a consulta de cada um dos autores previamente levantados e análise a partir dos resultados de buscas, foi possível extrair os autores com maior frequência de citações, isto é, com o corte superior a vinte ocorrências, a saber:

Quadro 1 - Ocorrência de citação dos autores das Ciências Sociais e Humanas na Biblioteconomia e Ciência da Informação

\begin{tabular}{|c|c|}
\hline Autores das Ciências Sociais e Humanas & Ocorrência na base BRAPCI \\
\hline Michel Foucault & 137 \\
\hline Pierre Bourdieu & 63 \\
\hline Jürgen Habermas & 64 \\
\hline Gilles Deleuze & 60 \\
\hline Paulo Freire & 40 \\
\hline Karl Marx & 45 \\
\hline Pierre Lévy & 39 \\
\hline Walter Benjamin & 32 \\
\hline Edgar Morin & 31 \\
\hline Mikhail Bakhtin & 29 \\
\hline Manuel Castells & 24 \\
\hline Bruno Latour & 27 \\
\hline Peter Berger & 20 \\
\hline Immanuel Kant & 20 \\
\hline
\end{tabular}

Fonte: Elaborado pelas autoras

Dentre os demais autores ${ }^{4}$, destacam-se ainda os mais citados entre dez e dezenove vezes, a saber: Umberto Eco (18 resultados); Erving Goffman (17 resultados), Theodor Adorno

\footnotetext{
4 Adam Smith; Agostinho de Hipona; Alain Touraine; Albert Camus; Alberto Guerreiro Ramos; Albrecht Wellmer; Alfred Schmidt; Alfred Sohn-Rethel; Alvin W. Gouldner; Anaximandro; Ann Oakley; Anthony Giddens; Antonio Gramsci; Aristóteles; Arquimedes; Auguste Comte; Augustine Brannigan; Axel Honneth; Basil Bernstein; Bernard Stiegler; Blaise Pascal; Boaventura de Souza Santos; Boécio; Bruno Latour; C. L. R. James; C. Wright Mills; Caio Prado Junior; Carlos Nelson Coutinho; Charles Tilly; Claude Lévi-Strauss; Clifford Geertz; Confúcio; Cornelius Castoriadis; Daniel Bell; Darcy Ribeiro; David Hume; David Lockwood; Demócrito; Donald Pierson; Donna Haraway; Dorothy Smith; Edgar Morin; Edmund Husserl; Edward Said; Émile Durkheim; Emilio Willems; Epicuro; Erasmo de Roterdão; Erich Fromm; Ernest Burgess; Ernest Gellner; Ernesto Laclau; Ernst
} 
(16 resultados), Friedrich Nietzsche (15 resultados), Max Weber (14 resultados), Roland Barthes (13 resultados); Zygmunt Bauman (13 resultados); Platão e Aristóteles (14 resultados cada autor), Thomas Samuel Kuhn (14 resultados); Ludwig Wittgenstein (13 resultados); Hilton Japiassu (12 resultados), Jean-Paul Sartre (10 resultados), Martin Heidegger (9 resultados), Gaston Bachelard (9 resultados), entre outros. Cumpre destacar ainda que os seguintes sociólogos brasileiros foram citados nos artigos indexados pela base de dados, pelo menos uma vez: Darcy Ribeiro; Sergio Buarque de Holanda; Gilberto Freyre; Florestan Fernandes; Octavio Ianni; Jessé José Freire de Souza. Por outro lado, registra-se uma quantidade significativa de autores das Ciências Sociais e Humanas que não foram citados na produção da Biblioteconomia e Ciência da Informação.

Esse resultado preliminar permitiu identificar os autores das Ciências Sociais e Humanas mais citados. Na verdade, em primeiro lugar, possibilitou afirmar que a Biblioteconomia e a Ciência da Informação evocam diferentes autores para a composição e construção de seu conhecimento. Considera-se esse momento de visibilidade fundamental para suscitar a verticalização de análises oriundas dos estudos bibliométricos, como pretende-se, em um segundo momento da pesquisa, analisar as citações de cada um dos autores a fim de responder porque eles são convocados. Não se pode perder de vista que as citações são um processo de cunho histórico, teórico, conceitual, metodológico, e que tais manifestações mobilizam redes e relações de saber-poder. Como forma de ampliar também a visibilidade dos autores das Ciências Sociais e Humanas na Biblioteconomia e Ciência da Informação, sugere-

Bloch; Erving Goffman; Everett Hughes; Fernando Henrique Cardoso; Florestan Fernandes; Francis Bacon; Frantz Fanon; Franz Josef Brüseke; Frederic Engels; Friedrich Hegel; Friedrich Nietzsche; Friedrich Pollock; Friedrich Schiller; Gabriel Tarde; Galileu Galilei; Gaston Bachelard; Gayatri Spivak; Georg Simmel; George Homans; Georges Gurvitch; Gilberto Freyre; Gilles Deleuze; Giordano Bruno; Gustavo Cardoso; Guy Debord; György Lukács; Harold Garfinkel; Henry Jenkins; Heráclito; Herbert Marcuse; Herbert Spencer; Hipócrates; Hilton Japiassu, Howard S. Becker; Immanuel Kant; Immanuel Wallerstein; Jean Baudrillard; Jean-François Lyotard; Jean-François Mattéi; Jean-Jacques Rousseau; Jean-Paul Sartre; Jessé José Freire de Souza; Johann Wolfgang Von Goethe; John Dewey; John Locke; John Stuart Mill; Judith Butler; Jürgen Habermas; Karl August Wittfogel; Karl Korsch; Karl Mannheim; Karl Marx; Leo Löwenthal; Loïc Wacquant; Louis Althusser; Louis Wirth; Lúcio Aneu Séneca; Ludwig Feuerbach; Ludwig Wittgenstein; Manuel Castells; Marilena Chaui; Marshall McLuhan; Martin Bulmer; Martin Heidegger; Mary Douglas; Maurício Tragtenberg; Max Horkheimer; Max Scheler; Max Weber; Melanie Klein; Michael Tye; Michel Foucault; Michel Maffesoli; Mikhail Bakhtin; Montesquieu; Nicolas Malebranche; Nicolau Maquiavel; Niklas Luhmann; Norbert Elias; Norberto Bobbio; Octavio Ianni; Orlando Patterson; Oskar Negt; Paul Gilroy; Paulo Freire; Pedro Demo; Peter Berger; Pierre Lévy; Pierre Félix Bourdieu; Pitirim Sorokin; Platão; Ralph Miliband; Randall Collins; Raymond Boudon; Renato Jose Pinto Ortiz; Renè Descartes; René Lourau; Richard Sennet; Robert Ezra Park; Robert McKenzie; Robert Merton; Robert Nozick; Roland Barthes; Rosa Luxemburgo; Schopenhauer; Sergio Buarque de Holanda; Siegfried Kracauer; Simone de Beauvoir; Sócrates; Stuart Hall; Sun Tzu; Talcott Parsons; Theodor Adorno; Thomas Hobbes; Thomas Humphrey Marshall; Thomas Luckmann; Ülrich Beck; Umberto Eco; Vilém Flusser; Viola Klein; Voltaire; Walter Benjamin; Wilhelm Wundt; William I. Thomas; William Julius Wilson; Zygmunt Bauman. 
se que a pesquisa seja feita na base de dados internacional LISA, a fim de possibilitar essa discussão epistemológica, bem como o relacionamento dos achados das pesquisas advindas de duas distintas bases de dados, e em diferentes momentos históricos.

\section{CONSIDERAÇÕES FINAIS}

A ciência, que se iniciou com a Filosofia ainda na Antiguidade, passou por transformações radicais ao longo dos séculos, tendo como ponto de virada a constituição das ciências modernas, na Modernidade. Na contemporaneidade, sob a marca das Ciências Sociais e das Humanas, diversos outros campos do conhecimento surgiram, dentre eles a Biblioteconomia e a Ciência da Informação. Como explica Boaventura de Sousa Santos (1988), uma mudança radical na história das ciências ocorreu com a crise do paradigma tradicional, embasado na lógica da ciência moderna e do positivismo, e nos valores da objetividade, método único, neutralidade, separação do sujeito e objeto. Assim, a instauração de um outro paradigma emergente, pautado na intencionalidade, na contradição, na diversidade de pensamento, é fucral para uma aproximação profunda dos referenciais teóricos das Ciências Sociais e Humanas.

Notadamente em decorrência da crise dos paradigmas ocorrida nas ciências, a visão restrita dos sujeitos e do mundo social passa por uma abertura, conduzindo a uma outra configuração mais integrativa e dialógica das pesquisas e dos pesquisadores. A Biblioteconomia e a Ciência da Informação como campos localizados nas Ciências Sociais, por sua vez, empregam metodologias, conceitos e teorias dessas ciências para a estruturação e construção de seu conhecimento de modo mais frequente, afastando-se de um pensamento positivista e do paradigma tradicional. Os problemas que são postos requerem uma abertura maior das pesquisas e dos pesquisadores, que, por meio da leitura e citação de outros autores, conformam uma abertura da Biblioteconomia e Ciência da Informação nas mais diversas temáticas que abordam.

Dito isso, constata-se a partir da pesquisa na BRAPCI a recorrência de autores clássicos e contemporâneos, sendo, portanto, possível perceber essa influência dos autores as Ciências Sociais e Humanas na construção e produção do conhecimento específico destes campos científicos. A presença desses autores revela uma complexidade de correntes de pensamento que se fazem presentes a partir da citação dos mesmos nas produções da Biblioteconomia e Ciência da Informação. Embora toda classificação apresente algum problema no enquadramento, de modo geral, os autores das Ciências Sociais e Humanas mais citados poderiam ser associados a uma vertente crítica, social e pós-estruturalista, demarcando a 
consolidação da Biblioteconomia e Ciência da Informação dentro de um paradigma social. Considera-se essencial a compreensão da análise de domínio da Biblioteconomia e a Ciência da Informação, as quais devem ser entendidas como campos científicos vinculados às Ciências Sociais, sendo a pesquisa mais produtiva quando os domínios do conhecimento são entendidos como comunidades de pensamento ou discursos, distanciando-se da abordagem tecnicista, positivista.

Posteriormente pretende-se ampliar a análise para uma investigação qualitativa com a finalidade de verificar quais teorias, conceitos e discursos dos autores mais citados são utilizados pela produção científica de tais campos, a fim de aprofundar e discutir as ocorrências e os enquadramentos realizados. Outros estudos poderiam ser assim encaminhados na direção das seguintes problemáticas: quais manifestações são possíveis de identificar a partir da análise de citação dos autores advindos das Ciências Sociais e Humanas? Qual a contribuição desses autores para a conformação epistemológica e/ou metodológica dos campos da Biblioteconomia e Ciência da Informação? 


\section{REFERENCIAS}

ALVARENGA, L. Bibliometria e arqueologia do saber de Michel Foucault - traços de identidade teórico-metodológica. Ciência da Informação, [S.1.], v. 27, n. 3, maio 1999.

ALVES, B. H.; OLIVEIRA, E. F. T. Conceitos da sociologia de Pierre Bourdieu e a Ciência da Informação. In: ENCONTRO NACIONAL DE PESQUISA EM CIÊNCIA DA INFORMAÇÃO, 18., 2017, João Pessoa. Anais [...]. João Pessoa, Universidade Federal da Paraíba, 2017.

AMORIM, I. S.; MEDEIROS, M. B. B. Apropriação da filosofia de Deleuze na Ciência da informação: um estudo quantitativo. InCID: R. Ci. Inf. e Doc., Ribeirão Preto, v. 8, n. 2, p. 69-91, set. 2017/fev. 2018.

ARAUJO, C. A. A.; BRAGA, R.M.O.; VIEIRA, W.O. A contribuição de C. Kuhlthau para a ciência da informação no Brasil. Revista digital de biblioteconomia e ciência da informação, Campinas, v. 7, p. 185-198, jan./jun. 2010.

ARAUJO, C. A. A.; LAGE, D.F.S.; SOUZA, R.M.F.; ASSIS, R.A. A contribuição de J.H. Shera para a ciência da informação no Brasil. Revista ACB, Florianópolis, v. 15, n.2, p. 7189, 2010.

ARAÚJO, C. A. Bibliometria: evolução histórica e questões atuais. Em Questão, Porto Alegre, v. 12, n. 1, p. 11-32, jan./jun. 2006.

ARBOIT, A. E.; BUFREM, L. S.; FREITAS, J. L... Configuração epistemológica da Ciência da Informação na literatura periódica Brasileira por meio de análise de citações (1972-2008).

Perspect. ciênc. inf., Belo Horizonte, v. 15, n. 1, p. 18-43, abr. 2010.

BRAPCI. Base de Dados em Ciência da Informação. Acervo de Publicações Brasileiras em Ciência da Informação. Paraná, 2017. Disponível em: http://old.brapci.inf.br/index.php. Acesso em: 02 out. 2019.

BUFREM, L. S.. A prática da pesquisa e os quadros teóricos concorrentes no campo de produção científica em ciência da informação. P2P \& INOVAÇÃO, Rio de Janeiro, v. 4 n. 1, p. 35-58, set./fev. 2018.

BOURDIEU, P. O campo científico. In: ORTIZ, Renato (Org.). Pierre Bourdieu. São Paulo: Ática, 2012.

CASTRO, J.; SILVA, L. Aspectos epistemológicos da Ciência da Informação: a transcendência da Teoria Crítica de Habermas e os paradigmas da Ciência da Informação.

Revista conhecimento em ação, Rio de Janeiro, v. 1, n. 1, p. 91-104, jan/jun. 2016.

CAPURRO, R. Epistemologia e Ciência da informação. In: ENCONTRO NACIONAL DE PESQUISA EM CIÊNCIA DA INFORMAÇÃO, 5., Belo Horizonte, 2003. Anais [....]. Belo Horizonte: Escola de Ciência da Informação da UFMG, 2003.

FARA, P. Uma Breve História da Ciência. São Paulo: Fundamentos, 2015. 
FELL, A. et al. A Produção Acadêmica no Brasil sobre Ciência da Informação: um estudo a partir da Teoria do Conhecimento de Habermas. Em Questão, Porto Alegre, v. 20, n.1, P. 127-150, jan./jun. 2014.

FOUCAULT, M. As palavras e as coisas: uma arqueologia das ciências humanas. 8.ed. São Paulo: Martins Fontes, 1999.

FRANCELIN, M. M. Epistemologia da Ciência da Informação: evolução da pesquisa e suas bases referenciais. Perspect. ciênc. inf., Belo Horizonte , v. 23, n. 3, p. 89-103, set. 2018.

KROEFF, M. S. et al. Análise de citações dos artigos publicados em periódicos da área da Ciência da Informação que versam sobre gestão da informação. Revista Brasileira de Biblioteconomia e Documentação, São Paulo, v. 11, n. 1, p. 41-65, jan./jun. 2015.

LALLEMENT, M. História das ideias sociológicas: das origens a Max Weber. Petrópolis, RJ: Vozes, 2008.

LUCAS, E. R. O.; SILVEIRA, M. A. S. (Org.). A Ciência da Informação encontra Bourdieu. Recife: UFPE, 2017.

MARTELETO, R.; SALDANHA, G. Informação: qual estatuto epistemológico. In: MORIGI, V.; JACKS, N. GOLIN, C. Epistemologias, Comunicação e Informação. Porto Alegre: Sulina, 2016.

MARTELETO, R.; PIMENTA, R. Pierre Bourdieu e a produção social da cultura, do conhecimento e da informação. Rio de Janeiro: Garamond, 2017. 370 p. E-book.

PINHEIRO, A.C.; SILVA, G.R.; ARAUJO, C. A. A. A contribuição de Tefko Saracevic para a ciência da informação no Brasil. Múltiplos Olhares em Ciência da Informação, Belo Horizonte, v. 1, n.2, p. 1-13, 2011.

ROMANCINI, R. O que é uma citação? A análise de citações na ciência. Intexto, Porto Alegre: UFRGS, v. 2, n. 23, p. 20-35, jul./dez. 2010.

SARACEVIC, T. Ciência da informação: origem, evolução e relações. Perspectivas em Ciência da Informação, v. 1, n. 1, p. 41-62, jan./jun. 1996.

SIEBENEICHLER, F. B. Considerações sobre o conceito de liberdade comunicativa na filosofia habermasiana. Logeion: Filosofia da Informação, [s. 1.], v. 1, n. 1, p. 43-58, out. 2014. Disponível em: http://revista.ibict.br/fiinf/article/view/1491/1669. Acesso em: 28 fev. 2020.

SILVEIRA, M. A. A. da; CAREGNATO, S. E., BUFREM, L. S. Estudo das razões das citações na ciência da informação: proposta de classificação. Tendências da Pesquisa em Ciência da Informação, [s.1], v. 2, n. 7, 2014.

SHIKIDA, A. M. da S. Construção e constituiçãa de uma ciência: análise bibliométrica e arqueológica do periódico Ciência da Informação. 2012. Tese (Doutorado em Ciência da Informação) - Escola de Ciência da Informação, Universidade Federal de Minas Gerais, Belo Horizonte, 2012. Disponível em: https://repositorio.ufmg.br/handle/1843/ECID-943PGA. Acesso em: 29 set. 2019. 
SANTOS, B. de S. Um discurso sobre as ciências na transição para uma ciência pós-moderna. Estudos avançados, São Paulo, v. 2, n. 2, p. 46-71, 1988.

TANUS, G. F. A constituição da biblioteconomia científica: um olhar histórico. RDBCI:

Revista Digital de Biblioteconomia e Ciência da Informação, Campinas, SP, v. 14, n. 2, p. 217-231, maio 2016.

TANUS, G. A Biblioteconomia como Ciência Social. In: SPUDEIT, Daniela; MORAES, Marielle de (Org.). Biblioteconomia social: epistemologia transgressora para o século XXI. São Paulo: ABECIN, 2018. 280 p.

VANTI, N. A. Da bibliometria à webometria: uma exploração conceitual dos mecanismos utilizados para medir o registro da informação e a difusão do conhecimento. Ciência da Informação, Brasília, v. 31, n. 2, p. 152-162, maio/ago. 2002.

VANZ; S., CAREGNATO, S. Estudos de Citação: uma ferramenta para entender a comunicação científica. Em Questão, Porto Alegre, v. 9, n.2, p. 295-307, jul./dez. 2003.

WOLFRAM, D. A pesquisa bibliométrica na era do big data: Desafios e oportunidades. In: MUGNAINI, R.; FUJINO, A.; KOBASHI, N. Y. (Org.). Bibliometria e Cientometria no Brasil: infraestrutura para avaliação da pesquisa científica na Era do Big Data. São Paulo: ECA/USP, 2017. 218 p. E-book.

ZATTAR, M.; LIMA, C. Habermas na literatura de Ciência da Informação: investigação das publicações na "Library and Information Science Abstracts" (LISA). Inf. Prof., Londrina, v. 2, n. 2, p. 158-175, 2013.

\section{BIBLIOGRAFIA CONSULTADA}

CHAUÍ, M. Convite à Filosofia. Ática, São Paulo, 2000.

FERNÁNDEZ MOLINA, J. C.; MOYA ANEGÓN, Félix. Perspectivas epistemológicas "humanas" en la documentación. Revista española de Documentación Científica, [S.1.], v. 25, n. 3, p. 241-253, sep. 2002.

HJØRLAND, B.; ALBRECHTSEN, H. Toward a new horizon in Information Science: domain-analysis. Journal of the American Society for Information Science, v.46, n.6, p.400-425, jul. 1995.

MOSTAFA, S. P.; AMORIM, I. S.; SOUZA, L. M. A Filosofia e discurso na ciência da informação: tessitura de encontros. Logeion: Filosofia da Informação, Rio de Janeiro, v. 1, n. 1, p. 6-19, 2014. 